\section{TRAUMATIC RUPTURE OF THE STOMACH}

\section{F. HECTOR SCOTSON, M.B., B.S.L.ND.,} F.R.C.S.ENG.,

LATE RESIDENT SURGICAL OFFICER, MANCHESTER ROYAL, INFIRMARY.

In the Glasgou Medical Journal of 1894, J. Grant Andrew, in a paper read before the Glasgow Pathological and Clinical Society in December, 1893 , reports a fatal case of traumatic rupture of the stomach due to a crush, for which no operation was performed. In his review of the literature, he states that ip to 1858 three cases of complete rupture of the stomach had been reported, and, including the one he rolatcd, there were eight further ones up to 1893. All these cases were fatal, some immediatcly following the injury, two heing five days after the injury. He makes a note that the rupture was generally near the pylorus, and that vomiting was frequent in most of the cases.

In Acute Abdomina? Disedses, published by Adams in 1923 , it is stated that minture of a normal stomach may be caused by violent contraction of the abdominal muscles, by blows, or by crusles. He states that the rupture is usually longitudinal, and near the prloric portion of the lesser curvature of the stomach, and the only pathognomonic signs are fresh blood in the romit and obliteration of the liver dullness-in addition, of course, to the usual signs of rupture of any abdominal viscus.

Sherren states that between the years 1899 and 1919 eleven cases of ruptured stomachs were admitted to the London Hospital, but in only three was it the sole viscus ruptured, and all these cases treated in the London Hospital died. He says that ruptures from external violence are usually situated in the region of the greater curvature. He also quotes Deaver and Ashurst as stating that only four operations for tramatic rupture of the stomach have been recorded, and all resulted in death.

Walton, in his Surgical Dyspepsias, states that traumatic rupture of the stomach is rare, and generally other viscera are affected. He quotes Sherren as saying that of 270 cases of abdominal contusion admitted to the London Hospital in ten years the stomach was ruptured in five, and in only one of these ases was no other viscus affected. He also quotes Battle, who published 165 cases of intestinal injury, but no example of injury to the stomach. Walton states that practically all reported cases of rupture have occurred when the stomacli is full, and that rupture takes place at the weakest part of the wall-namely, the greater curvature. Owing to the severity of the injury and the frequency of the accompanying lesions these injuries are nearly always fatal.

I thought it would be interesting for me to publish (with the kind permission of Professor Burgess and Mr. Wrigler, under whose care thess patients were while at the Manchester Royal Infirmary) two (ases which I operated on, and in which the rupture of the stomach was the only abdominal injury present, and both of which made uninterrupted recoveries, each patient being discharged from the Infirmary in a fortnight.

CASE I.

Mrs. J. G. was admitted to the hospital on July 14th, 1928, following the injuries she received by her car colliding with another one, the impact doubling her up and throwing her under the dashboard. When I examined her she was pale, she had vomited once following the accident, the abdomen was rigid, she was suffering severe abdominal pain, and there was diffuse tenderness and guarding all over the abdomen, more especially at the right side. There was no shifting dullness to be detected in the flanks. Her pulse rate was 92 , and temperature $99^{\circ} \mathrm{F}$. There were no other signs of injury anywhere to be made out. On the diagnosis of the rupture of an intestinal viscus, I made a right rectus slide incision, and on opening the peritoneum I found blood and extravasated contents in the abdominal cavity. These were swabbed out, and rupture about the size of a threepenny piece was found at the pyloric end of the stomach near the lesser curvature. The rent was sutured with interrupted I Lembert sutures of catgut, and the abdomen was then closed, with drainage to the abdominal wall. She was discharged home on July 28th.

CASE II.

Mr. A. F. was admitted to the Manchester Royal Infirmary on December 18th. He could not give any account of the accident, as he was suffering from some slight degree of concussion of the brain. I learnt from wituesses that he had been knocked off a pedal cycle by a motor bus. A neighbouring doctor, who saw him immodiately after the accident, gave him $1 / 4$ grain of morphine. When I saw him lie was complaining of abdominal pain, and also the abdomen was generally rigid and tender. His pulse was 70 , strong and steady, and the temperature $97^{\circ} \mathrm{F}$. At operation I found much free blood, gas, and stomach contents in the abdominal cavity. These latter were swabbed out. The stomach was inuised and ocdematous, and there was a rent about an jnch long high up on the lesser curvature of the stomach, which was sutured, as in the previous case. The abdominal cavity was then filled with hot saline solution and the abdomen closed. The wound healed by first intention, and he was discharged to the convalescent home on December 31st.

Both these rases were caused by injuries when the stomach was full, and both were operated on within eight hours of the acrident. In one case the upper part of the lesser (nuvature of the stomach was affected, and in the other the pyloric portion of the stomach. In neither case were there any other abdominal injuries, either internal or external. The immodiate after-treatment was similar to that employed in the case of rupture of a gastric or duodenal ulcer.

I have examined both patients about four months after the injurios, and neither complains of any disability.

\section{TOXIC JACNDICE WITH ASCITES.}

BY

ERNEST BLLMER, M.I)., M.R.C.P.ED., M.R.C.P.Loxd.,

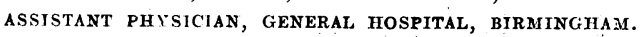

Althorgh the occurrence of ascites in cases of toxic jaundice is a relatively uncommon happening, it is probable that its frequency is considerably greater than the rery sparse literature would suggest. I have given much attention to certain aspects of liver disease, and naturally a fair concentration of liver cases has occurred in my practice; it was not until recently, however, that an example of the srudrome under consideration came under my care. A search of the literature disclosed only four references to it, and $I$ felt that a brief review of the subject rould not be devoid of interest.

Fiessinger and Brodin ${ }^{1}$ and Fiessinger and Walter $^{2}$ give a very clear account of their conception of what they have termed the "studrome ictéro-ascitique," and their description, both of the clinical features and of the pathology, cannot be bettered. During the course of a multilobular cirrhosis of the liver the clinical picture oceasionally becomes dramatically altered by the sudden onset of ascites and jaundice. This jaundice, they say, is not the usual subicteric tint of the cirrhotic, but a frank icterus with deep coloration of the integuments, bile in the urine, and (lay-coloured stools. Ascites develops rapidly, but the amount of the effusion, and the necessity for frequent tapping, vary widely in different cases. At the same time the patient's general condition degenerates rapidly, emaciation and marked weakness ensue, and there are usually digestive troubles; fever may appear, and its explanation is a matter of some difficulty.

The progress of the malady is variable; usually the condition is rapidly fatal, and the presence of the srndrome may be taken to mean the presence of an acute or subacute hepatitis-cholaemia may carry off the patient with its familiar train of symptoms. Some patients recorer, however, and these are the ones in whom some definite cause can be found for the onset of toxic jaundice-the transitory toxaemia of surgical anaesthesia, the action of novarsenobillon, etc. Where no cause can be found the outlook is grave.

With regard to the pathology of the condition these author's describe a widespread fatty degeneration of the parenchymal cells of the liver, together with the usual findings of atrophic cirrhosis. Their explanation of the syndrome is ingenious; it is obvious that acute hepatitis in a normal liver would produce jaundice, and in such a liver the swelling of individual cells would result in an increase in the volume of the organ. If such a hepatitis arose in a cirriotic liver jaundice would naturally cnsue, but the fibrosis of the organ would prevent, in crrtain 
cases, any increase in volume, and the swelling of the liver cells could only occur by encroachment on the portal capillaries with consequent portal obstruction. The work of Azoulay and Jaquelin ${ }^{3}$ gives important confirmation to this contention. They found that the healthy human liver after death would increase and diminish in volume according to the pressure of the fluid with which it was perfused, but in a cirrhotic liver practically no volume changes could be produced.

Willcox ${ }^{4}$ quotes two cases of an analogous but not exactly comparable type occurring as a result of tetrachlorethane poisoning; after many weeks of toxic jaundice symptoms of portal obstruction developed. There is, however, a definite probability that in these cases the obstruction was due to replacement fibrosis. There are, of course, other explanations, and the case quoted by $\mathrm{Halita}^{5}$ of toxic jaundice of four months' duration with generalized anasarca cannot be accounted for on these lines. Halita regarded the dropsy as due to an upset in the metabolism of water, probably as the result of an alteration of the colloidal balance of the plasma.

The frequent oedema of the ankles in cases of preascitic cirrhosis has been similarly ascribed. There is no reason why the two explanations should be mutually exclusive, as the two types of case are not clinically identical. A third explanation for the ascites is that it is caused hr peritoneal irritation, and this cannot be denied; Fiessinger's views are, however, too alluring to be lightly spurned.

The case that came under my observation was that of a man ared 52; he was first seen in August, 1928, with the history that his Wassermann reaction two years before had been strongly positive and that he had then been successfully treated with novarsencbillon for paroxysmal tachycardia. The complaint had recurred, and a further course was suggested. Apart from rather an interesting tachycardia of the paroxysmal type there was nothing on examination, but the Wassermann reaction in the blood was strongly positive. He received six injections of 0.3 gram of novarsenobillon, a total of 1.8 grams, and his treatment was stopped on November 6th, as jaundice had developed. He was treated by his own doctor for some weeks, but as the jaundice did not clear up he was referred to me again on December 16th. He had a deep jaundice with bile in the urine and clay-coloured stools, and it appeared to be a case of rather severe toxic icterus. He was treated with the intravenous injection of sodium thiosulphats, and he received in all 4.5 grams. The jaundice increased rather than diminished, and the liver could be felt about two fingerbreadths below the costal margin; ascites developed, and it became gross and of sufficient amount to produce oedema of the legs. $\mathrm{He}$ was scnt back to his doctor on December 28th, and a very bad prognosis was given, with the suggestion that it must be a case of cancer of the liver, and the suggestion of toxic jaundice incorrect: He remained in bed for fifteen weeks, and both jaundice and ascites gradually cleared. He had become very emaciated, but it was now obvious that he was going to recover. On May 23 rd I saw him again; he was rather thin, but there were no signs of jaundice; the liver appeared to be the same size as it had been at the leight of the disease. Retrospectively the case was then diagnosed as an cxample of the ictero-ascitic syndrome, and it is difficult to see what else it could be. Liver function tests were carried out with the following results: Van den Bergh test negative. Icterus index 2. Levulose tolerance test: before levulose, blood sugar 0.098 ; half an hour after 50 grams, $0.154 ; 1$ hour after, 0.168; $1 \frac{1}{2}$ hours after, $0.132 ; 2$ hours after, $0.115 ; 2 \frac{1}{2}$ hours after, 0.108 ; Galactose tolerance test : before, 0.108 ; half an hour after 50 grams, $0.141 ; 1$ hour after, $0.162 ; 1 \frac{1}{2}$ hours after, $0.110 ; 2$ hours after, $0.105 ; 2 \frac{1}{2}$ hours after, 0.086 .

It will be seen that both of the sugar tolerance tests show a definite abnormality in the functional capacity of the liver; this confirms my view of the pathology of the case-an initial cirrhosis of the liver, possibly of syphilitic origin, and a superimposed arsenical jaundice complicated by ascites.

Finally, due acknowledgement must be made to Mr. Garfield Thomas, biochemist to the General Hospital, for the chemical findings.

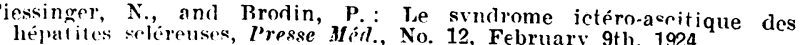
hépatites sclérenses, Prosse Mstr., No. 12, February 9th, 1924 .
Fipesinger, N., and Waltor, H.: L'prploration fonctionnelle du foie,
Masson it Cie, Paris, 1925, pp. 291--295. 8 Azoulay, R., and Jaquelin, A. : Compt. Rent. Soc. de Biol. 1924, xc, 1157 4 Willox, Sir William : Discussion on Jaundice, British Medical Journal, 1924 , ii, 500.

- Halita, M.: Ictère toxi-infectiense avec hydropisie, Bntl. et Mím. Soc. Méd. des Hôp. de Parig, No. 27, A ugust 4th, 1927, p. 1266
THE DICK TEST IN PREGNANCY.

Report on 533 Cases in the Obstetrical Unit of the Royal Free Hospital.

BY

MARGAPET SALMOND, M.D., B.S.LoND., M.R.C.S., L.R.C.P.,

SENior assistant, obstetrical aNd GYNaECological UNit;

AND

\section{BEATRICE TURNER, F.R.C.S.ED., M.B., B.S.LoND., M.R.C.S., L.R.C.P.,} OBSTETRICAL AND GYNAECOLOGICAL REGISTRAR.

Is the Lancet (April 14th, 1928, pp. 746, 748) there were two interesting articles by Dr. Parish and Dr. Okell on the relationship of the haemolytic streptococci to scarlet fever and other diseases. The authors suggested that the closest relationship existed between the streptscocci of puerperal fever and scarlet fever. It obviously became of great interest to see if there were any agreement between the reaction of pregnant women to the Dick test and their liability to puerperal sepsis. A paper by BurtWhite ${ }^{1}$ suggested that there was a definite relationship. The following investigation was also designed to test the hypothesis that such a relationship exists. Shortly after our work was begun the British Medical Association most generously awarded us a research grant, which has considerably facilitated the investigation.

In all, 533 cases have been tested. The test is performed as is described below on patients when they come into hospital in labour. Messr's. Burroughs Wellcome's standardized scarlet fever toxin and control are used. An intradermal injection of $0.2 \mathrm{c.cm}$. of toxin is made into the patient's left forearm, and $0.2 \mathrm{c.cm}$. of control into the right forearm.

The reactions are noted in six hours, and again in twelve to eighteen hours. Positive reactions begin to fade in about twenty-four hours. A positive reaction is indicated by an area of erythema, varying in size, surrounding the point of injection in the left forcarm. Occasionally an erythematous area is also seen on the control arm. If there is an area of erythema only on the control arm a protein reaction is indicated, and this is also shown by areas of erythema of equal size on both arms. If there are erythematous areas on both, but that on the left is larger than that on the right, the reaction is positive. No erythema at all indicates a negative reaction. It is also of interest to note when doing the test whether the patient has previously had scarlet fever, erysipelas, puerperal ferer, or severe sore throat.

The results of the tests are as follows, the Queen Charlotte's standard of morbidity $\left(100^{\circ} \mathrm{F}\right.$. on one occasion at any time during the puerperium) having been used:

1. Of the 533 cases tested 158 (or 29.6 per cent.) were Dick-positive, 373 (or 69.9 per cent.) were Dick-negative, and 2 (or 0.3 per cent.) had protein reactions only.

2. Among the Dick-positive cases 126 (or 80 per cent.) remained afebrile throughout the puerperium, and 32 (or 20 per cent.) were at some time febrile, according to the above-named standard morbidity. Among the Dick-negative cases 317 (or 85 per cent.) remained afebrile, and 56 (or 15 per cent.) were febrile. In all, there were 443 (or 84 per cent.) afebrile patients, and 88 (or 16 per cent.) febrile patients.

3. An analysis of the afebrile and febrile cases in relation to complications yields the following statistical data: manipulations were necessary in the delivery of 50 Dickpositive patients and 140 Dick-negative patients; of the former, 14 (or 28 per cent.), and of the latter, 30 (or 21 per cent.) were febrile. Of the 108 remaining Dickpositive cases, in whose treatment manipulations were not undertaken, 18 (or 17 per cent.) were febrile; and of the corresponding 233 Dick-negative cases 26 (or 11 per cent.) were febrile. A history of previous attacks of scarlet fever, erysipelas, sore throat, etc., was obtained from 42 Dickpositive and from 123 Dick-negative cases. Of the former, 5 (or 12 per cent.), and of the latter, 22 (or 18 per cent.) were febrile. Among the 116 Dick-positive cases giving lin such history 84 (or 72 per cent.) were febrile, and among 